\title{
IMPLEMENTATION OF HUMAN CROWD AS SELLING BOOSTER ON SALES BRAND PROCESS
}

\author{
Ina Melati Indartoyo ${ }^{1 *}$, Annetta Gunawan ${ }^{1}$, Haryadi Sarjono ${ }^{1}$ \\ Bina Nusantara University, Jakarta, Indonesia 11480 \\ *imelati@binus.edu
}

\begin{abstract}
The quality of Mount Puntang Coffee is very famous amongst foreign countries, even it has been recognized world widely as one of the best coffee in the world. However, it does not necessarily make Mount Puntang's coffee easy to market and sell. One of the parties that feels the is impacted by it is Haben Nagen, a brand and coffee shop owner who is also a farmer and become a part of the Mount Puntang coffee lovers community. From a short interview conducted to the people live in Bandung and Jakarta, on the average they answered that they did not know Gunung Puntang coffee, they also did not know if Mount Puntang coffee was one of the best coffees in the world. If Indonesian people, especially the people around West Java, don't know the quality of coffee from Mount Puntang, how are they interested in buying it?. For this reason, the solution offered to the owners of the Haben Nagen coffee brand is to create an artificial offline crowd in the form of a human crowd on 2 (two) locations which are their sales channels, namely: 1). Haben Nagen coffee shop, and 2). The exhibition booth where Haben Nagen participated in it. Human crowd is an artificial crowd which is formed from a certain number of people, which is used as a special treatment that aims to attract the attention of people outside the crowd to join in the human crowd and do the same thing done by people in the crowd. In a shorter discussion, the human crowd serves as the attention of the public, so that the surrounding people become more aware of a brand / product where human crowd is implemented, and then make an impulsive purchase.
\end{abstract}

Keywords: Community, human crowd, coffee brand and impulsive purchase

\section{INTRODUCTION}

In the city of Bandung there is also a village that has tremendous potential as a tourist destination that can be proud of, namely Wangun Village. One of the interesting things from Wangun Village is most of the people take the initiative to develop their village's core competence in the form of natural resources in their area by becoming craftsmen or communities that manage these natural resources into products that are worth selling. Some groups of craftsmen or communities in this village are called: 1). Shoe craftsmen and 2). Coffee farmers

Some coffee farmers in the village of Wangun then joined and later called themselves with the community, under the command of Mr. Encid as the chairman of the Mount Puntang coffee-lovers community. The name of the community according to Mr. Encid has certain meanings and philosophies, namely: coffee from Mount Puntang is planted with love and affection by coffee farmers who love coffee, so the coffee produced has a good taste. The farmers treat the coffee like a child themself, who must be cared for wholeheartedly to grow into a good child, in this case certainly the best coffee in the world.

One of the potential of Wangun Village to become rural tourism is very high, of course because of its coffee resources. Even Wangun Village managed to become a rural coffee tour. In addition to coffee, Wangun Village is also pilot project for nine other villages that have different potential, not just coffee. So if all of these potentials are maximized, then Wangun Village will become an independent village with a lot of potential that can be developed to benefit its people.

The simplicity of the coffee farmers culture and the uniqueness of Puntang's coffee are very attractive to local tourists and especially foreign tourists to attend this village. They can enjoy Puntang coffee served by native farmers who know very well how to process this coffee and enjoy life together 
with local villagers like Puntang's coffee farmers with their traditional conditions which are very interesting and meaningful. The fatigue of the atmosphere in the city with its modern culture will make traditional phenomenon of the famous Puntang Coffee farmers be interesting to be enjoyed as a tourist attraction.

Some of the local people from Mount Puntang who are also members of the Mount Puntang coffee lovers community are trying to take advantage of the opportunity, by strive several sales strategies, such as: labeling it with a unique brand name, opening a shop and also participating in several tourism and culinary themed exhibitions. From the community of Mount Puntang coffee lovers, was born a brand name selling coffee Mount Puntang, namely: HABEN NAGEN.

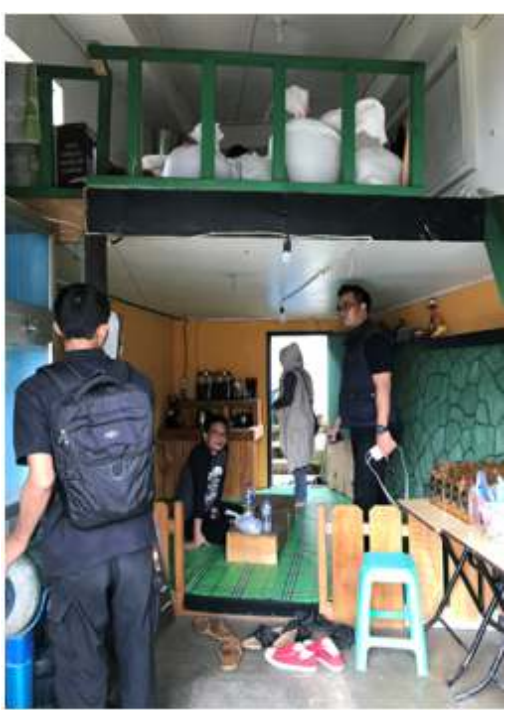

Figure 1. Coffee Shop "Haben Nagen"

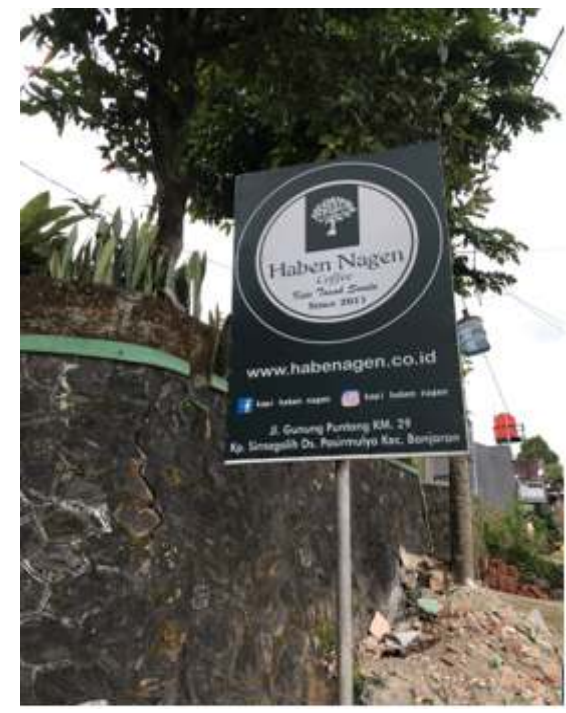

Figure 2. Coffee Brand "Haben Nagen"

Haben Nagen indeed had not been opened for too long, but its potential as a coffee shop is promising. Similarly with the Mount Puntang coffee brand which even though they don't have a store yet but has a very promising product potential with a brand name that is also quite unique and very special that describes the origin of the product.

\section{Problems}

Even though Haben Nagen has a high value, but their brand is currently still not well-known by society of Indonesia, even in the city of Bandung itself. A interview was conducted to find out the awareness of the people in Bandung to the Haben Nagen brand, and the average of respondent said they did not know this kind of brand.

But other than the quality of the products, Haben Nagen offers other unique things, in the from of: a unique experience, that by offering a different kind of coffee drink experience to coffee lovers who come directly to the store. The blend between the amazingly delicious coffee products which is made directly in its place where visitors can see the whole coffee making process directly and even get involved through it, plus the atmosphere around the shop that supports it, makes Haben Nagen very worthy to get a approval inside of the hearts in Indonesian coffee lovers. 


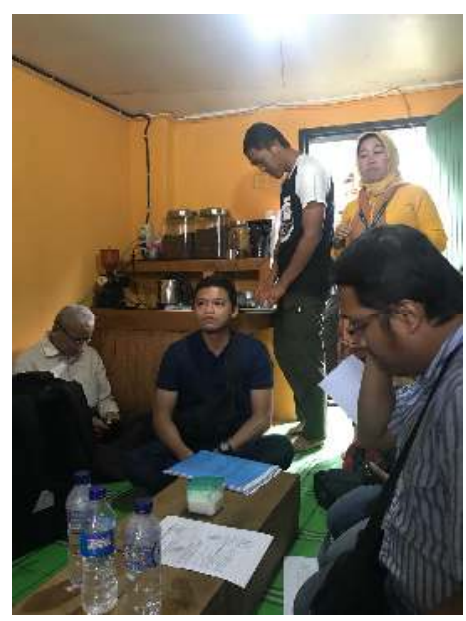

Figure 3. Whole Coffee Making Process in Haben Nagen Coffee Shop

It seem that Haben Nagen been experience problems that have also been experienced by other Small Medium Enterprises, even though it not a new product, but its brand sounds new to most society of Indonesian, even society in the city of Bandung which is the closest market for both Small Medium Enterprise. So that when their brand is not too well-known, then the public's buying interest in these two brands will be reduced or even non-existent.

For Haben Nagen, when the opportunity open the store at an event in the center city of Bandung, the store was lack with visitors, and the products were unable to compete with other brands that sold the same product, where brand competitors were much crowded, that's why they needed to manage the human crowd. Crowd that is well managed and structured will make Haben Nagen store "more visible". The quantity from the human crowd created by Haben Nagen is expected to make the crowd even bigger and will affect the individuals outside the crowd to approach Haben Nagen store and then buy their products.

\section{Solution}

The application of knowledge for the development of the culinary tourism business world is realized by implementing human crowd as a selling booster for Haben Nagen. Although Haben Nagen sells one of the best coffee products in the world but this does not necessarily make them easily increase sales, in this case their sales stagnant time to time, the number of buyers does not show significant improvement. As a result there is not much business development that they can do, this clearly has an impact on the introduction of Mount Puntang coffee products was stagnating and it is like a road in a place like circle that is difficult to expand and develop.

That is why it is necessary to apply the selling booster treatment for these two brands in order to increase sales by implementing human crowd treatment. Human crowd treatment itself is a treatment in the form of a group of people in a certain amount positioned around the business locations of the two partners (store or exhibition booth) in order to give impression of being crowded and attractive to the general public to visit the stores or exhibition booths of the two partners. In theory, the implementation of human crowd is not only based on the Herd Behavior theory proposed by Banerjee (1992). In theory of herd behaviour it said that is a situation where an individual behaves because of the influence of other individuals.

Crowd is actually a dilemma for the retail world, on the one hand retail store owners will be happy if the retail store is crowded, because it means many buyers will buy their products, but on the other hand, crowd will make consumers feel uncomfortable, encouraging the desire to buy more, which it will affects the income that will be produced by a retail stores. Buyers tend to influence each other, including the decision to buy a product, include this case the crowd is considered as positive thing because it can influence other buyers to buy (Tversky \& Kahneman, 1974) .

In other words, if there is no asymmetric information, or special conditions that are very influential, an individual in behaviour will tend to follow the behaviour of the individual beforehand. 
In this case an individual will rationally follow what is done by many individuals, the more individuals do it, the more individuals follow, so in this case herd behaviour is very likely to create a crowd. The bandwagon effect explains the same thing. In this theory its explained that an individual will tend to follow the individual's behaviour before, if the proportion of individuals who do it is major, in other word the more individuals who do that, the more other individuals will do what same (hop on the bandwagon) Banerjee (1992) Conformity theory is one theory that can explain the form of a crowd. In an experiment known as an ash experiment, it was revealed that an individual would tend to follow the same behavior carried out by six other individuals, the seven individual who saw this, would to the same thing done by six previous individuals, then a group of individual will did the same thing at the same time and in the same place will naturally form a real human crowd. In the context of marketing, especially in the aspect of purchase, conformity theory describes changes in consumer evaluation, interest in buying or behavior occurs due to exposure to evaluation, interest, or buying behavior referenced by other parties (Lascu \& Zinkhan, 1999).

In the context of the retail environtment, retail density has an influence on a consumer's buying decision, more specifically explained that retail density can influence consumers in making impulsive purchases. In the context of retail density especially human crowd, real human-crowd can moderate the influence between retail density with impulsive buying.

Some studies focus on the negative aspects caused by the crowd in the context of the retail environment. Density in the context of the retail environment in this case crowd will make consumers feel uncomfortable, encouraging the desire to immediately move from retail stores, and impact on the reduced desire of buyers to buy more, which of course affects the income that will be produced by retail stores (Earls, 2003).

However, it turns out that many studies also produce positive impacts from the crowd in the context of the retail environment. Buyers tend to influence each other, including terms of the decision to buy a product, so in this case the crowd is considered a positive thing because it can affect other buyer to buy. In a study also produced a finding that retail density influences purchasing decision impulsively.

\section{Strategy Implementation}

Human Crowd Implementation is carried out for one time in a period of six months, with 3 training sessions for owners and operators of the two brand of coffee to conduct human crowd treatment.

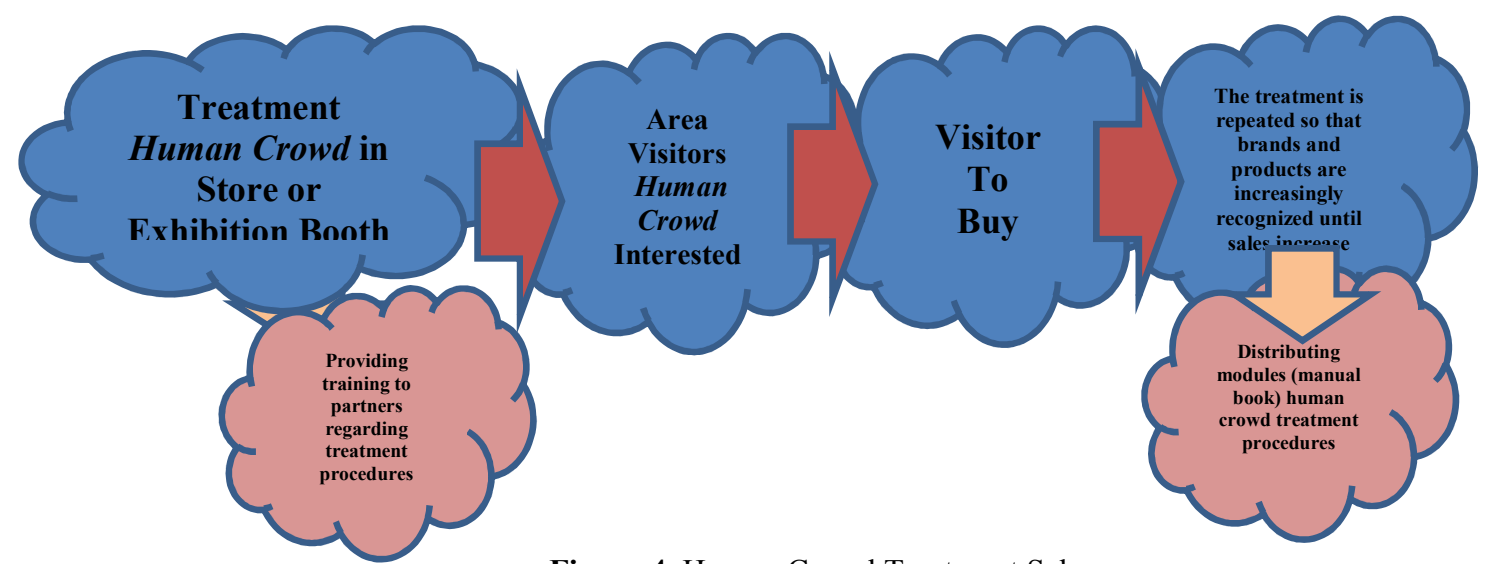

Figure 4. Human Crowd Treatment Scheme

With implementation plans of the crowds as follows :

\section{Human Crowd's Schedule Implementation in Haben Nagen}

\begin{tabular}{|l|l|l|}
\hline Event & Location & Time \\
\hline $\begin{array}{l}\text { Exhibition Event (Archery } \\
\text { Competition) }\end{array}$ & Mount Puntang & May 2018 \\
\hline
\end{tabular}


City of Bandung has a phenomenon Mount Puntang, one of the phenomenon thing is coffee, many famous store in big city like Indonesia buy directly the coffee beans from community of coffee lovers from Mount Puntang.

\section{RESULT AND DISCUSSION} Coffee:

The following are the visualization human crowd at booth Haben Nagen and Mount Puntang

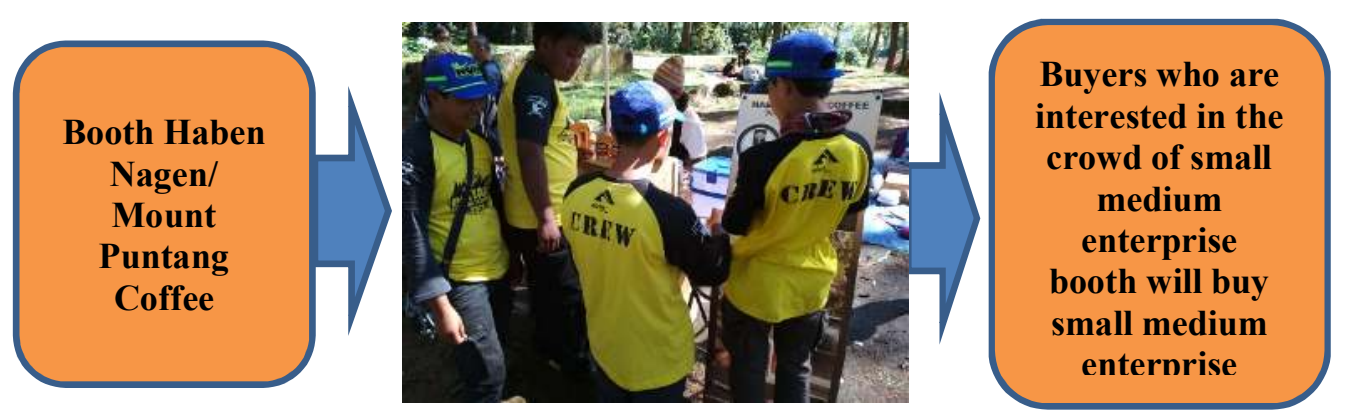

Figure 5. Human Crowd Implementation

From one times of implementation treatment human crowd, sees like there is many people outside crowd who were initially not interested with Haben Nagen stores, furthermore to buy the coffee or interested in the human crowd. It is also very suitable for usage on product with low customer engagement, till when human crowd is applied to the product of Haben Nagen Coffee, then the result is pretty good (Laurent \& Kapferer, 1985).

In the survey to see the effect of human crowd that shared to the buyer of Haben Nagen coffee, as much of two times of distribute survey, is before the buyers see the crowd and after the buyer see the crowd, seems like average of buyers answers that they interested to visit the store of Haben Nagen, because trigerred by the human crowd, and then they are interested to buy Haben Nagen Coffee also because they seem like seeing many people buy Haben Nagen coffee, although they seems like doesn't have the desire to buy this coffee. this thing becomes a very interesting of invention, because human crowd is not only get a coffee store become more crowded and interesting, however is also trigger the people around to do the same thing by the people of human crowd, that is to buy Gunung Puntang Coffee until human crowd itself also the trigger to buy impulsively. Impulsive purchase itself is a pretty good thing for the product with the new brand or the product with the unknown brand, because the impulsive purchase will make people to buy the new product, try the product, and people interest to try the product are on of the initial goals which is very desirable by the owner of the product with the new brands.

\section{CONCLUSION}

Human crowd treatment is a strategy to increase sales (selling booster) which is worth to try by entrepreneurs who are just starting a business. Because human crowd treatment if applied correctly can cause a new crowded sensation on the location business of new entrepreneurs, and impact of people around will interested in the crowd and next to buy the new product that sold by the new entrepreneurs.

However on the implementation, entrepreneurs need to pay attention in several things so that crowd treatment will give you a maximum of positive impact that is: 1). Wide business location, where treatment human crowd will be applied, 2). Estimate the total of visitors, this thing is important because will influence how major the human crowd and 3). Often implementation of treatment, this things is important because more often of treatment is done then of course people will increasingly interested into the treatment of human crowd, until the people are familiar with the product. 


\section{REFERENCES}

Banerjee, A. V. (1992). A Simple Model of Herd Behavior. The Quarterly Journal of Economics, 107(3), 797-817. http://doi.org/10.2307/2118364

Earls, M. (2003). Advertising to the herd: how understanding our true nature challenges the ways we think about advertising and market research. International Journal of Market Research, 45, 311-336. Retrieved from http://youmakethemeaning.com/downloads/Earls_Herd.pdf

Lascu, D.-N., \& Zinkhan, G. (1999). Consumer Conformity: Review and Applications for Marketing Theory and Practice. Journal of Marketing Theory and Practice, 7(3), 1-12. http://doi.org/10.1080/10696679.1999.11501836

Laurent, G., \& Kapferer, J.-N. (1985). Measuring Consumer Involvement Profiles. Journal of Marketing Research, 22(1), 41. http://doi.org/10.2307/3151549

Tversky, A., \& Kahneman, D. (1974). Judgment under Uncertainty: Heuristics and Biases. Science, 185(4157), 1124-1131. http://doi.org/10.1126/science.185.4157.1124 